\title{
DEFINING THE CONCEPT OF RISK APPLIED IN ENTREPRENEURSHIP. CONCEPTUAL DELIMITATION RISK - ENTREPRENEURIAL UNCERTAINTY
}

\author{
TĂRĂBÎC ANDREI ALEXANDRU \\ West University of Timisoara, Romania
}

(C) 2019 Andrei Tărăbîc

This is an open access article distributed under the Creative Commons Attribution-NonCommercial-NoDerivs license (http://creativecommons.org/licenses/by-nc-nd/3.0/)

DOI: 10.1515/eras-2019-0004

\begin{abstract}
Even though in many cases the terms of risk and uncertainty are similar, they have to be delimited to understand the meaning of each, individual, as accurately as possible. The two terms are combined in different situations. No matter how well the risk is managed, uncertainty cannot be removed because all possible situations and interdependencies cannot be taken into account. Thus, a source of risk can be considered uncertainty in itself if it is based on poor quality information about the actual internal or external situation of the company. Also, in my conclusion, traditional financial theory distinguishes between systematic risk and particular risk, which reaches the company's overall risk. Investors can reduce total risk with the two primary risk management instruments, namely diversification and asset allocation.
\end{abstract}

\section{Keywords}

entrepreneur, risk, uncertainty, SME's

\section{Introduction}

The evolution of risks can have a significant effect on profits, even on the survival of the company, so it is very important to try to keep them under control. The risk is the result of the use of resources, through which the entrepreneur can suffer probable losses or will have lower incomes than planned. The concept of risk when referring to an investment can be perceived not only as the danger of not reaching the desired level, but also as a probability of going beyond what is desired. Managing it can mitigate the negative effects it can have on business, and success can only be achieved through a proper risk-benefit assessment.

Entrepreneurs may have a perception of risk, which may be different from what determines them to make a decision. A cause of this issue is the concern of managers to present risk by value-added, without using modern methods of estimating it (statistical, probabilistic calculation). Another aspect is the preference of describing the risk to the detriment of its quantification, considering only partially possible events, instead of considering the results as a whole. Risks that an economic entity has to manage give arise to two approaches or cultures of risk: one that rejects the risk and another that accepts it (Griffiths, 2005). The culture that rejects the risk is characterized by stability, experience, centralized management and the needs of the clients being put in second place after the efficiency of the internal organization of the activities. 
On the other hand, this perception of risk gives rise to the lack of initiative of the employees, leading to the lack of strategies and the lack of innovation leads to skepticism. The culture that accepts the risk is exactly the opposite of the other: open to innovation, the determinants being novelty, motivation, exploitation of specific opportunities.

Decisions are passed on to all employees, customers are at the forefront and the continuous change in strategies reflects adaptation to existing circumstances. The two cultures are characteristic of the following types of risk management: culture that rejects risk is characteristic of traditional risk management; culture that accepts risk is characteristic of modern risk management.

\section{Theoretical background}

The term is derived from the French ,risque” of the 17th century and is defined by the French explanatory dictionary Le petit Larousse as danger, the more or less likely inconvenience to which we are exposed or exposure to a hazard, loss or failure. The explanatory dictionary of the Romanian language defines it as "the possibility to reach a danger ... or to bear a damage: a possible danger" (Coteanu, 1998, 929).

A research of early financial literature shows many discussions about risk, but only few definitions. There are two trends specific to the 20th century in defining risk: subjective probability and operationalism. The most famous definition of risk is that of Frank Knight in 1921, in his paper Risk, Incertitude and Profit. The definition given by Knight is as follows: „To preserve the distinction between measurable uncertainty and unmeasurable uncertainty, we can use the term risk to designate the prime and the uncertainty term for the latter" (Knight, 1921, 233). The given definition quantifies risk through objective probability and uncertainty through subjective probability.

When it comes to the risks that can affect an organization's activity, namely economic risks, its classification is known by numerous criteria. We will list some criteria for their classification:

1. The nature of the risks may be: pure risks (events that can not be controlled, representing insurable events (natural calamities, wars, etc.); speculative risks (there is probability of both loss and gain; these are manageable through management techniques).

2. According to their location, there are: macroeconomic risks; sectoral risks; microeconomic risks.

3. According to their foreseeability the risks may be: predictable risks, which are generated by predictable factors; unpredictable risks from unanticipated factors.

4. According to the phenomenon belonging: internal risks, which are the result of the company's activity; external risks, which depend on the environment in which the company operates;

5. Depending on the consequences of the risks may be: exploitation risks, which reflect the variation in the result when changing the conditions of the activity; financial risks, which reflect the variation of the result according to the financing policy; bankruptcy risks that show the company's solvency through its ability to meet its current payment obligations.

The terminology of risk varies from one organization to another, so practitioners working in different organizations may use distinct terms to refer to the same risk or the same nomenclature for different risks.

There are five types of different classifications used by the various regulatory bodies and insurance companies listed below (Kelliher et al., 2011, 21): the Book of the Financial Services Authority of the United Kingdom (FSA); German Federal Financial Regulatory Authority (BaFin); The Lloyds Bank Group; UK Life and Financial Services Prudential plc.; Working Group of Statistical Professionals in Risk Classification. 


\section{Methodology}

The theoretical and methodological approach of the studied issue has as reference the current and the reference research in the field and the information activity provided that can highlight the concepts and processes existing in literature and in the practice of organizations. At national level, there are works that deal with cost-benefit issues by using, in particular, traditional cost-effectiveness analysis indicators. The issue addressed in the case study by using modern indicators of profitability, in correlation with those of risk, is not the subject of the empirical studies conducted in our country up to this point. Treating the two approaches in parallel - using modern and traditional indicators - highlights the differences between the two studies, delivering results that can meet any company goal, from maximizing profits, lowering costs, etc. to increasing value.

\section{Findings}

The approaches of other theorists from this period refer to subjective interpretations (probabilities are human convictions) and objectives (probability is real, estimated by statistical analysis) of probability.

According to subjective interpretations, probabilities are not intrinsic to nature, but they characterize their own uncertainty (Holton, 2004, 19). Knight's definition provides an objective perspective of risk and refers to the intrinsic probability of a sentence being true or false by determining the likelihood (subjective process) in two ways: the a priori probabilities that are derived from the pure risk and the statistical probabilities obtained on based on homogeneous data. The definition given by Knight is as follows: „to preserve the distinction between measurable uncertainty and unmeasurable uncertainty, we can use the term risk to designate the first and the uncertainty term for the latter" (Knight, 1921, 233).

The given definition quantifies risk through objective probability and uncertainty through subjective probability. A critique of this definition is that it is not a definition of risk in reality. According to common use, the risk involves both uncertainty and possible consequences of exposure. Harry Markovitz, the researcher who developed the modern portfolio theory, states in his $\mathrm{PhD}$ thesis: "The concepts of yield and risk appear frequently in the financial literature. If the term yield was replaced by the expected return, the term of risk with the variation in profitability would result in a small change of meaning" (Haslett, 2010, 117), suggesting that the change in profitability is close to identifying the risk.

The economic risk is defined as: "an unsafe event or process that is likely to cause damage, loss in an activity, operation or economic activity" (Niţă, 1999, 408); "a future event and probably the production of which could cause some losses. It can be predictable when factors ... can be anticipated and unpredictable, determined by situations whose possibility ... is totally uncertain" (Pantea et al., 2012, 39); "risk is the chance that the current return on investment will be different from the expected outcome. The risk includes the probability of losing some or all of the initial investment "(Gallatti, 2012, 191); "the uncertainty of a result, taking the form of a positive opportunity or of a negative threat to actions or events, must be managed in the light of a combination of the possibility of something happening and the impact that it would bring to materialize possibilities "(HM Treasury, 2004, 9); "the possibility of an event occurring and adversely affecting the achievement of objectives" (Coso, 2004).

There is an evolution in the definition of risk, moving from the probability of a loss, predictable or unpredictable, to another possible form - the opportunity, from its impact that may affect an activity, operation, to hindering the achievement of the objectives. If risk connotation is generally negative, recently the notion of risk also includes the significance of 
better outcomes than expected, because risk can show opportunities to improve the objectives of a project.

The risk has the following features: is a possible, predictable or unpredictable event the risk originates in uncertainty; is a generally negative event, whose definitions contain the terms of uncertainty and loss, but can also refer to the term of opportunity, denoting a positive connotation; is an event in all human activities, whose effects can no longer be removed; represents the distribution of the expected results; is the result of choices made.

\section{Conclusions}

In conclusion, traditional financial theory distinguishes between systematic risk and the particular risk, which reaches the company's overall risk. Investors can reduce total risk with the two primary risk management instruments, namely diversification and asset allocation. Also theoreticians and practitioners with modern visions of profitability and risk consider a fundamental issue how the boards of directors are addressing risk measurement. The boards of directors focus on the framework accounting and do not take into account the associated risk to its true size. Net profit, established as the primary objective, should result in a return on capital higher than the post-tax credit rate. Gross profit, set as the sole objective, has as a single condition a capital return greater than zero. Adapting the accounting framework to create an apparent view of effectiveness leads to important adjustments of financial indicators that create a false picture of the economic and financial situation.

\section{REFERENCES}

Committee of Sponsoring Organizations of The Treadway Comission (2014), Improving Organizational Performance and Governance: How The COSO Frameworks Can Help; COSO (Enterprise Risk Management - Integrated Framework, 2004:5)

Coteanu (1998), Decizia in afaceri Risc si incertitudine in afaceri. Decizie si negociere

Gallatti, R.R., Investment Discipline: Making Errors Is Ok, Repeating Errors Is Not Ok, Bloomington, IN: Balboa Press

Griffiths, P. (2005), Risk-Based Auditing, Gower Published Limited, Aldershot, England

Haslett Jr., W.V. (2010), Risk Management. Foundation for a Changing Financial World, CFA Institute, Ed. John Wilesy\&Sons

H. M. Treasury (2004), The Orange Book. Management of Risk - Principles and Concepts, https://www.gov.uk/government/uploads/system/uploads/attachment_data/file/220647/orange_book.pdf

Holton, G.A. (2004), Defining Risk, Financial Analysts Journal Volume 60, Number 6, CFA Institute

Kelliher P.O.J., Wilmot D., Klumpes VIJ, J., Klumpes, P.J.M. (2011), Risk Classification Working Party. A common risk classification system for the actuarial profession, http://www.actuaries.org/lyon2013/papers/AFIR_Kelliher_Wilmot_Klumpes.pdf

Knight, F. H. 1921. Risk, Uncertainty, and Profit, New York: Hart, Schaffner, and Marx

Pantea, M.I., Munteanu, V., Gligor, D., Sopoian, D. (2008), The Managerial Performances Evaluation through the Economic Value Added

Niță, D. (1999), Dicționar de Economie, Ed. Economică, București 